\title{
La acupuntura resultó eficaz como tratamiento de diferentes tipos de dolor crónico
}

\author{
Acupuncture was an effective treatment for different types of chronic pain
}

\section{Objetivos}

Evaluar la efectividad de la acupuntura en el tratamiento de diferentes tipos de dolor crónico comparándola contra tratamiento habitual y/o acupuntura placebo.

\section{Fuentes de datos}

MEDLINE, Registro Central de Ensayos Controlados de la Colaboración Cochrane, Clinicaltrials.gov.

\section{Selección de estudios}

Ensayos clínicos controlados y aleatorizados en los que se hubiera comparado la eficacia de la acupuntura contra el tratamiento habitual y/o acupuntura placebo en dolores crónicos (cefalea, omalgia, osteoartritis, dolor de columna no específico de duración mayor a cuatro semanas). Solo se incluyeron aquellos artículos en los que el proceso de ocultamiento y aleatorización había sido claro y adecuado. No se estableció un tipo de resultado a evaluar de ante-
Vickers AJ y cols. Arch Intern Med. 2012;172(19):1444-1453

mano dada la variabilidad de las patologías evaluadas.

\section{Extracción de datos}

Se obtuvieron los datos crudos de los trabajos seleccionados. Se evaluaron y clasificaron los artículos según su probabilidad de sesgo de ocultamiento*. Para el análisis de sensibilidad solo se incluyeron aquellos artículos clasificados como de baja probabilidad de sesgos.

\section{Resultados Principales}

Dada la gran variabilidad en la medición de los resultados de los diferentes trabajos, los resultados de cada trabajo individual fueron convertidos en puntajes estandarizados, lo que permitió calcular una medida sumaria de efectividad estandarizada). Se comparó acupuntura contra acupuntura placebo y también acupuntura contra control no acupuntural (en la mayoría de los casos, cuidado habitual). Ver tabla 1.

Tabla 1: resultados de la comparación de tratamientos de acupuntura contra placebo y contra controles que no incluyeron acupuntura en pacientes con varios tipos de dolor crónico.

\begin{tabular}{|c|c|c|c|c|c|c|c|c|}
\hline \multirow[b]{2}{*}{ Tipo de dolor } & \multicolumn{4}{|c|}{ Acupuntura contra acupuntura placebo ${ }^{\mathrm{a}}$} & \multicolumn{4}{|c|}{ Acupuntura contra control que no incluyó acupuntura ${ }^{\mathrm{a}}$} \\
\hline & $\begin{array}{c}\text { Nro. } \\
\text { de artículos }\end{array}$ & $\begin{array}{c}\text { EF } \\
(\mathrm{IC95} \%)\end{array}$ & $\begin{array}{c}\text { EA } \\
(\mathrm{IC95} \%)\end{array}$ & P- heterog. & $\begin{array}{c}\text { Nro. } \\
\text { de articulos }\end{array}$ & $\begin{array}{c}\text { EF } \\
\text { (IC95\%) }\end{array}$ & $\begin{array}{c}\text { EA } \\
(\mathrm{IG95 \% )}\end{array}$ & P- heterog. \\
\hline Dolor de columna no específico & 8 & $\begin{array}{c}0,37 \\
(0,27 \text { a } 0,46)\end{array}$ & $\begin{array}{c}0,52 \\
(0,14 \text { a } 0,90)\end{array}$ & & 7 & $\begin{array}{c}0,55 \\
(0,51 \text { a } 0,58)\end{array}$ & $\begin{array}{c}0,51 \\
(0,36 \text { a } 0,67)\end{array}$ & \multirow{3}{*}{$<0,001$} \\
\hline Osteoartritis & 5 & $\begin{array}{c}0,26 \\
(0,17 \text { a } 0,34)\end{array}$ & $\begin{array}{c}0,37 \\
(0,03 \text { a } 0,72)\end{array}$ & $<0,001$ & 6 & $\begin{array}{c}0,57 \\
(0,50 \text { a } 0,64)\end{array}$ & $\begin{array}{c}0,57 \\
(0,29 \text { a } 0,85)\end{array}$ & \\
\hline Cefalea crónica & 4 & $\begin{array}{c}0,15 \\
(0,07 \text { a } 0,24)\end{array}$ & $\begin{array}{c}0,15 \\
(0,05 \text { a } 0,24)\end{array}$ & 0,31 & 5 & $\begin{array}{c}0,42 \\
(0,37 \text { a } 0,46)\end{array}$ & $\begin{array}{c}0,38 \\
(0,22 \text { a } 0,55)\end{array}$ & \\
\hline Omalgia & 3 & $\begin{array}{c}0,62 \\
(0,46 \text { a } 0,77)\end{array}$ & $\begin{array}{c}0,62 \\
(0,46 \text { a } 0,77)\end{array}$ & 0,44 & 0 & & - & \\
\hline
\end{tabular}

${ }^{a}$ En educción de puntos de desvío estándar. EF: efectos fijos. EA: efectos aleatorios.

\section{Conclusión}

La acupuntura mostró ser un tratamiento eficaz para varios tipos de dolor crónico con efecto moderado.

\section{Comentario}

La acupuntura como técnica terapéutica de la Medicina Tradicional China está documentada desde hace al menos 3000 años. Sin embargo, su evaluación rigurosa desde el punto de vista metodológico, solo data de las últimas tres décadas. Esto se relaciona con la necesidad de la Medicina Occidental de entender los procesos biológicos que subyacen en los tratamientos acupunturales. Por esta razón se ha colocado mucho énfasis no solo en el estudio a nivel molecular de los efectos de las agujas en el cuerpo, sino también en poder evaluar si la acupuntura es solo un potente placebo.

Más allá de la importancia que se ha dado a la evaluación de la acupuntura como placebo, sería muy interesante dejar de lado ese concepto y asumirla como una técnica que claramente explota el efecto de la capacidad natural de la auto-sanación.
Teniendo esto como punto de partida, resultaría de gran utilidad contar con mayor número de trabajos que comparen la eficacia y la costo efectividad de la acupuntura en modalidad "Caja negra" contra tratamientos farmacológicos.

\section{Conclusión}

A pesar de los numerosos trabajos publicados en este campo, son muy pocas las investigaciones que alcanzan niveles acep-tables de la calidad metodológica. Este meta-análisis de datos individuales nos presenta la mejor evidencia disponible al momento y nos permite ampliar el abanico de opciones te-rapéuticas en una patología tan compleja como el dolor crónico. 